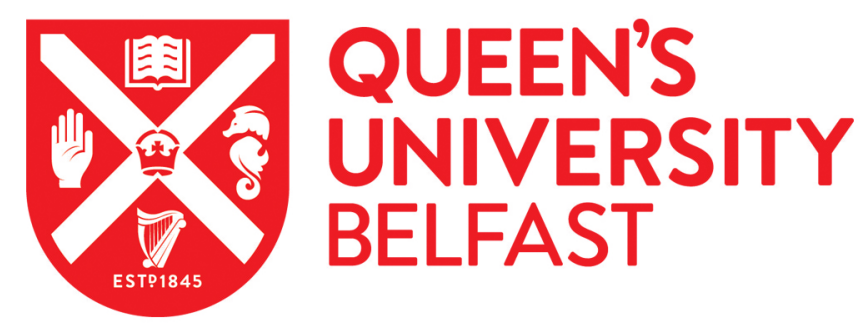

\title{
Recycling ceramic waste powder: effects its grain-size distribution on fresh and hardened properties of cement pastes/mortars formulated
} from SCC mixes

Ferrara, L., Deegan, P., Pattarini, A., Sonebi, M., \& Taylor, S. (2019). Recycling ceramic waste powder: effects its grain-size distribution on fresh and hardened properties of cement pastes/mortars formulated from SCC mixes. Journal of sustainable cement-based materials. https://doi.org/10.1080/21650373.2018.1564396

Published in:

Journal of sustainable cement-based materials

Document Version:

Peer reviewed version

Queen's University Belfast - Research Portal:

Link to publication record in Queen's University Belfast Research Portal Publisher rights
@ 2019 Informa UK Limited, trading as Taylor \& Francis Group. This work is made available online in accordance with the publisher's
policies. Please refer to any applicable terms of use of the publisher.

General rights

Copyright for the publications made accessible via the Queen's University Belfast Research Portal is retained by the author(s) and / or other copyright owners and it is a condition of accessing these publications that users recognise and abide by the legal requirements associated with these rights.

Take down policy

The Research Portal is Queen's institutional repository that provides access to Queen's research output. Every effort has been made to ensure that content in the Research Portal does not infringe any person's rights, or applicable UK laws. If you discover content in the

Research Portal that you believe breaches copyright or violates any law, please contact openaccess@qub.ac.uk. 


\title{
Recycling ceramic waste powder: effects its grain-size distribution on fresh and hardened properties of cement pastes/mortars formulated from SCC mixes
}

\author{
Liberato Ferrara ${ }^{1}$, Peter Deegan², Andrea Pattarini ${ }^{3}$, \\ Mohammed Sonebi ${ }^{4}$ and Su Taylor ${ }^{4}$ \\ ${ }^{1}$ _ Politecnico di Milano, Department of Civil and Environmental Engineering, liberato.ferrara@polimi.it (corresponding \\ author) \\ 2 - Banager Precast, Ltd., Banager, Ireland \\ ${ }^{3}$ - Azichem Ltd., Goito, Italy \\ ${ }^{4}$ - Queen's University of Belfast, School of Natural and Built Environment, Belfast, Northern Ireland, UK
}

\begin{abstract}
This paper presents the results of a preliminary study assessing the feasibility of using waste ceramic powder as a partial replacement of cement and/or sand in cement pastes and mortars. Two different ceramic powders, featuring different grain size distributions, have been employed, one from crushed bathroom fixtures and dental prosthesis waste and a second one from foundry industry residuals. With reference to cement pastes and mortars formulated from SCC mixes employed in precast industry, cement replacement volume percentages equal to $10 \%$ and $30 \%$ have been considered for each powder. The possibility of hydrid cement and sand replacement with either powder has also been addressed. Effects of the replacement on the workability, shrinkage, compressive and flexural strengths have been considered, up to 3 months curing.

The results confirmed the possibility of using this kind of waste in concrete, thus reducing the demand for raw cement and the burden on disposal landfills.
\end{abstract}




\section{Introduction}

Concrete being the second largest used material worldwide, after water, the "concrete community" can significantly contribute to increasing the sustainability signature of our current "life-style" and, in particular, of the construction sector as a whole. This actually continues to represent, despite the well-known negative economic trends of the past decade, a significant share of the gross domestic product in both developed and emerging countries. At the same time, Construction and Demolition (C\&D) activities produce, according to recent estimates, $75 \%$ of the waste due to all human activities. It has been claimed that one of the most significant environmental burdens of the whole life cycle of concrete is represented by the production of Portland cement. This is mainly due to the depletion of natural resources (limestone, clay etc.) and the high energy necessary for the production of clinker. It is thus evident that any effect to reduce the demand for cement or towards a low-clinker cement or alternative binders, such as geo-polymers, has a high sustainability value.

With reference to the first concept, the use of cement substitutes, with mere "inert filler" function or featuring either pozzolanic and/or cementitious additions (fly ashes, silica fume, ground granulated slag etc.) is now a well consolidated practice in the cement and concrete industry. This is well documented, noting the benefits in terms of improved performance in the fresh and hardened state as well as with reference to enhanced durability, resulting, e.g., from higher matrix compactness [1]. The aforementioned cement substitutes are by-products or waste materials from activities other than construction "proprie dicta", ranging from quarrying to electric power or steel production. Such advances invite novel research activities aimed at assessing the feasibility of using different kind of materials as cement replacement or substitutes. There is a tremendously wide variety of waste products available from a likewise wide range of human activities. Examples ranging from agriculture (natural fibres) to $\mathrm{C} \& \mathrm{D}$ wastes (recycled concrete aggregates for the production of recycled aggregate concrete) [2] as well as to daily consumer products (aggregates and fibers from recycled PET bottles) $[3,4]$ are gaining wider and wider popularity and acceptance in practice as well as in standards and structural design codes worldwide. 
In this framework, it is worth remarking that a conspicuous share of the C\&D waste $(54 \%$ according to recent estimates) is represented by ceramic materials (blocks, tiles, electrical insulation, bathroom fixtures), to which waste from the medical sector (anatomical and dental prostheses) and the ceramic production sector (up to $2 \%$ of the total production, depending on the degree of automation and quality control) have to be added. It would be thus of the foremost interest and importance to assess the feasibility of employing such a waste in a suitable form as a replacement/substitute either for cement and/or of natural aggregates in the production of concrete and cementitious composites [5]. Using ceramic waste in concrete production has been increasingly attracting researchers and practitioners in the last decade, both as replacement of cement [6-8] and as a raw material for the production of alternative clinkers [9-11]. Pozzolanic activity of the waste has been confirmed, which has led to setting some upper bound limits on the ceramic-to-cement replacement ratios (35\%), in order to temper the negative effects on strength development [10]. This is due to both later hydration of the pozzolana as well as to the lower availability of calcium hydroxide necessary to activate the same pozzolanic reaction. Incorporation of ceramic waste into cement and concrete was also effective in limiting the leaching of toxic substances such as zinc, boron and zirconium, normally employed for surface glazing of tiles and ceramic artifacts. Coarser ceramic waste particles were also used as a replacement of natural fine and coarse aggregates $[12,13]$ in the concrete, highlighting their potential as internal curing agents and also demonstrating that with a well balanced natural to recycled replacement ratio (20\%) compressive strengths as high as $100 \mathrm{MPa}$ can be achieved [14]. Moreover, because both waste ceramic powder and fine aggregates generally feature wider grain size distribution than cement and river sand, higher matrix compactness could be achieved, with reduced pore sizes [14]. The reduced pore size also resulted into vs., e.g., chloride attack [15].

Recently, the use of residues obtained from porcelain stoneware tiles polishing sludges have been also successfully employed to reduce/suppress alkali silica reaction when glass waste, of different origins (production of tableware, giftware and crystal decor item as well as of farmaceutical containers), was employed in substitution of natural aggregates [16]. 
Tailored combinations of different types of waste materials can thus be successfully employed for designing greener and greener high performing building materials.

In this study, the feasibility has been investigated of partially replacing cement or/and sand with ceramic powder originating from waste bathroom fixings/dental prosthesis and from foundry industry residuals. The two different ceramic waste powder were employed as provided by the recycling company, with the aim of maximizing their recyclability into concrete mixtures, at the same time reducing as much as possible the use of natural resources (sand) and cement into the formulation and production of the same mixtures. In the interest of simplicity, reference has been made to cement pastes and mortars, formulated from Self Compacting Concrete (SCC) mixes, in which up to $30 \%$ by volume of cement and/or sand has been replaced with ceramic powder. Since the mere replacement of cement with ceramic powder results in a modification of the actual water-to-cement (w/c) ratio, a tailored mix-design strategy has also been adopted, in which fixed w/c and ceramic-to-cement replacement ratios have been input as the optimization variables. Results, with reference to shrinkage behaviour as well as to compressive and flexural strength of the investigated pastes and mortars, seem to confirm that ceramic powder can be effectively incorporated into concrete without detriment on the mechanical properties.

\section{Experimental programme}

\section{$\underline{2.1 \text { Ceramic powders }}$}

The two different employed ceramic waste powders comes from disposed bathroom fixtures/denthal prosthesis (identified as $1^{\text {st }}$ ceramic powder henceforth) and from residues of foundry industry (referred to as $2^{\text {nd }}$ ceramic powder in the forthcoming paragraphs). Their composition, analysed by means of XRD, is shown in Figure 1a-b, highlighting that they consist of silica and alumina, as also confirmed by previous investigations [12]. It is anyway worth remarking that the different sources of the two investigated ceramic powders affected the form in which silicon and aluminum oxides were 
present. The first one contained almost pure silicon and aluminum oxide (Figure 1a), in the form of quartz (peak at around $25^{\circ}$ ) and corundum, with lower presence of alumino-silicate silimanite. On the other hand, in the second one, more complicate forms of the same oxides are present, such as zircon and mullite, a silicate mineral found in refractory porcelain resulting from different firing and melting processes.

Particle size analysis with laser diffraction method was also performed for both powders (Figures 2ab). The first powder has a significant fraction of sub-micron (nano)-sized particles; moreover, more than $90 \%$ of the particles have a diameter lower than $10 \mu \mathrm{m}$. This would result in increased matrix compactness. On the other hand the second powder is much coarser, with more than $90 \%$ of the particles larger than $100 \mu \mathrm{m}$, hence coarser than cement grains and somewhat comparable to the sand employed in mortar casting.

This will have interestig outcomes on the mechanical hardened state properties of cementitious composites made by replacing cement with either powder, as it will be furthreon elucidated.

\subsection{Paste and mortar mixes: mix-design and characterization}

Their effects as cement replacement has been investigated with reference to cement pastes and mortars, formulated from SCCs, the composition of which is listed in Tables 1 and 2. It is worth remarking that first of all, for both powders, their use as cement replacement has been invesigated, with reference to two different volume percentages, equal to $10 \%$ and $30 \%$. The replacement quantities have been calculated with reference to a density equal to $3100 \mathrm{~kg} / \mathrm{m}^{3}$ and $2000 \mathrm{~kg} / \mathrm{m}^{3}$ for the cement and ceramic powders respectively. In the latter case, an "alternative" composition has been also proposed, which also keeps the w/c weight ratio unaltered, by suitable scaling of the dosage of all constituents. For the second ceramic powder, its role as replacement of either cement or sand in the mortar has ben investigated. Finally, only with reference to mortars, the possibility of employing either the $1^{\text {st }}$ powder as a respective replacement of cement and the $2^{\text {nd }}$ as sand replacement 
has been addressed, also exploiting, in designing the related mix compositions, the results obtained from the previously performed assessment with reference to each single powder.

Fresh state performance has been the first to be investigated by means of slump flow tests.

With each mix, prism specimens 40x40x160 mm have been cast, these are tested in bending and compression according to EN 196-1. Tests have been performed at 1, 3, 7, 28, 56 and 84 days, also to assess potential pozzolanic activity, if any. Specimens were cured in a moist room at $20^{\circ} \mathrm{C}$ and 95\% RH until testing. For each testing age three specimens were cast; the data-base consisted of three flexural strength and six compressive strength values for each mix at each testing age (compression test is performed on each beam-half, after breaking the specimen in bending). Similar specimens have been also employed to test the development of total and autogenous shrinkage, for all the investigated pastes and mortars (EN 12617-4. For autogenous shrinkage, the samples, equipped with suitable end gauges, were wrapped in an aluminum foil and the length change was measured by means of a digital reader. In both cases measurements started $24 \mathrm{~h}$ after casting, when it was first possible to demould the specimens. Mercure Intrusion Porosimetry (MIP) tests have been performed on some $28 \mathrm{~d}$ mortar samples made by replacing cement with the 1 st ceramic powder to check the effects of its grain size distribution on the pore size distribution.

\section{Results and discussion}

\section{$\underline{3.1 \quad \text { Fresh state performance }}$}

Results of mini-slump flow tests of mortars (pastes have excessive flow and therefore the test is not significant), are shown in Tables 3-4, this highlighted that the substitution of cement with ceramic powder slightly affected, or better moderately improved, the mortar flowability, provided the water/powder ratio was kept constant. For the mixture obtained by scaling the dosage of constituents in order to keep the w/c ratio constant, similar flowability could be obtained only by increasing the dosage of superplasticizer in tandem. Because of its smaller particle size, the first waste ceramic 
powder is able to provide a lubricant effect to the cement, as is common for extra-finely ground cement substitutes. Interestingly, the addition of ceramic powder also seemed to result into slightly less dispersed values of the mini-slump flow diameter, most likely because of the higher particle grain size distribution and hence higher specific surface of ceramic powder. This favoured absorption of some extra water contributing to the increase in the mixture robustness. Despite is lower grain size distribution, the second ceramic powder provided similar fresh state performance as the former, most likely the porosity of the particles, higher than that of silica sand ones, and the amount of sub-10 $\mu \mathrm{m}$ particle fraction concurring to provide anyway the aforementioned lubrication effects. When replacing sand the second ceramic powder had a somewhat worsening effect on the folowability, as witnessed by the higher dosage of superplasticizer needed to obtain comparable fluidity. The synergy effect between the first and the second powder resulted in the need of a much higher superplasticizer dosage to obtain moderate level of fluidity.

\subsection{First ceramic powder substitution: compressive and flexural strength of pastes and mortars}

In Figures $3 \mathrm{a}-\mathrm{b}$ and $4 \mathrm{a}-\mathrm{b}$, the time evolution of the compressive and flexural strengths of pastes and mortars made with the first ceramic powder are presented. It can be observed that for low ceramic to cement replacement volume ratios, the likely pozzolanic activity of the former was able to compensate at quite later ages, the effects of cement reduction and proportional increase of the w/c ratio. For higher ceramic to cement replacement ratios, the aforementioned negative effects could only be overcome, by keeping constant the w/c ratio constant. The sole pozzolanic activity of the ceramic, as reasonably hypothesized on the basis of its mineralogical composition as compared to results available in the literature, was not able to provide a compensation, probably also due to the likely lower availability of the cement hydration products (portlandite), necessary for its activation. In the case of mortars, these negative effects are strongly reduced, also because of the "stabilizing" effect provided by the fine aggregate. This accounted for about $46 \%$ of the mortar volume fraction, and thus led to hypothesize that this effect could be even less evident in a concrete mix, if the paste 
volume fraction became even lower.

The same statements hold firm with reference to flexural strength (Figure $4 a-b)$. Quite surprisingly, after an almost constant trend for intermediate ages, the flexural strength seemed to decrease for longer age, always more dramatically for cement pastes than for mortars. This could be partially explained with progressive stiffening and embrittlement of the composites with aging. This makes it more difficult for the sectional redistribution of bending stresses, which is a distinctive feature of the test.

MIP test results (Tables 5 and Figure 5) show, at a first glance, that the total porosity is only moderately affected by the replacement of cement with ceramic powder. A deeper analysis of the results showed that the first ceramic powder, thanks to its grain size distribution and despite its slower reaction and the lower availability of cement was able to guarantee not only an unaltered total porosity but also lower average and median pore radii. The increase in w/c also did not affect the results. In detail, as from the curves shown in Figure 5, it clearly appears that the partial substitution of the cement with the first type of ceramic powder helps in almost eliminating the peak of porosity with diameters between 0.1 and $1 \mathrm{~mm}$. This, also confirming the findings reported in [15], would contribute towards an improved durability, the potential hazard vs. aggressive substances being correlated to the pore radius.

\subsection{Second ceramic powder substitution: compressive and flexural strength of pastes and mortars}

In the case of the second ceramic powder the aforementioned negative effects in cement pastes (Figure 6a) are evident only at very early ages, differences between the different investigated replacement ratios being lower than in the previous case and, from 7 days curing onward, pastes containing ceramic always performing better than the reference one. It can be reasonably claimed that the coarser ceramic grains make the paste to behave more like a mortar than a paste, thus smoothing, also thanks to the presence of harder grains, the effects of a reducing cementitious activity. The reliability of holding constant the w/c ratio to guarantee the performance is confirmed also in this 
case. In the case of cement mortars cast with the second ceramic powder (Figure 6b), the negative effects of cement substitution with cement reappear, with the same ratio as discussed above with reference to first ceramic powder. It can be argued that the particle size distribution of the ceramic powder and of the sand may negatively interact, not having been jointly optimized for compactness, since the sole cement-to-ceramic volume replacement criterion has been followed. Anyway also in this case, the mortar with $30 \%$ cement-ceramic replacement and constant $\mathrm{w} / \mathrm{c}$ ratio provided the best performance. With reference to the flexural strength of pastes and mortars cast with the second ceramic powder, the same statements hold as above for mixes cast with the first (Figures $7 \mathrm{a}-\mathrm{b}$ ).

\subsection{Hybrid substitution with first and second ceramic powder}

The use of the second ceramic powder to substitute $30 \%$ by volume of the sand or the synergy of the first and second powder, replacing $30 \%$ by volume of cement and sand respectively, always keeping constant the w/c ratio also proved a viable solution, as witnessed by the graphs in Figure 8 a-b, showing the time evolution of compressive and flexural strength of mortars featuring the same w/c ratio but different replacement solutions. Interestingly, the coarseness of the second ceramic powder had a positive synergy with the sand one, as far as the crack-arrestor effect of coarser particles in concerned which contributed to enhance the toughness of the composite and hence resulted into an increased flexural strrength.

\subsection{Shrinkage}

Results of shrinkage tests (Figures 9-10), confirm the effectiveness of cement to ceramic replacement also in reducing this kind of deformation, generally the higher the volume percentage replacement the higher the measured reduction of shrinkage deformation. This cast positive shadows also with reference to the overall durability of cementitious composites obtained with the investigated cement replacements. Effects are more visible in the case of total shrinkage, most likely because of the alterations in w/c ratios yielded by a mere volume replacement of cement with ceramic. As a matter 
of fact if the w/c ratio was kept constant, improvements also in the case of autogenous shrinkage were fairly evident. The second ceramic powder likely provided better performance than the former, probably because of a somewhat higher solid skeleton stability due to its coarser grains. As a matter of fact, improvement in mortar performance was always fairly better than that of corresponding pastes. The worse performance of pastes with $10 \%$ ceramic to cement replacement could be due a somewhat higher porosity cause by the coarser ceramic grains. When the second ceramic powder is employed as replacement of the sand no improvement, as expected, is achieved; anyway the benefits due to the replacement of the cement with the first ceramic still hold when contemporary replacement is performed of cement and sand with first and second ceramic powder respectively (Figure 11).

\section{Concluding remarks}

In this study a preliminary assessment has been performed of the feasibility of replacing cement with waste ceramic powders, obtained from disposed bathroom fixture/dental prostheses and from foundry industry residuals, in cement pastes and mortars.

The following concluding remarks hold:

- replacement of cement with ceramic powder yields to a moderate strength decrease in the short term, which is compensated, at later ages by some kind of pozzolanic activity of the ceramic. This will obviously also depend on the mineral composition of the ceramic waste and has to be investigated from case to case. The strength decrease can also be compensated by designing the mix composition so to keep constant the water to cement ratio.

- the grain size distribution of the ceramic powder also plays an important role, also with reference to the interaction with the grain particle size distribution of the other powders and aggregates.replacement of cement with ceramic powder also reduces the total and autogenous shrinkage deformation developments. This also pave the way to produce concrete with reduced early age cracking potential and hence higher durability, even with low w/c ratios, 
where the autogenous shrinkage deformation may be substantial, because of the positive mitigation effects yielded by the cement to ceramic replacement.

- negative effects on the fresh state performance can be easily overcome by suitably adjusting the SP dosage. Stabilizing effects of fine aggregates in mortars have been also highlighted, which led to hypothesize that good results are going to be obtained with reference to concrete mixtures, with the further presence of coarse aggregates.

This prodromal study, which seems to confirm literature findings about the upper bound for cement replacement ratio, is going to be completed with concrete-level durability investigation, in order to pave the way for the use of sustainable concrete incorporating waste ceramic powder for building engineering applications.

Synergy effects obtained replacing, in mortar and concrete mixtures, both cement and fine aggregates with ceramic powders coming from different sources and featuring different particle size distribution are also worth being investigated with the aim of improving the sustainability and $\mathrm{CO}_{2}$ footprint of cement based construction materials.

\section{Acknowledgements}

The authors wish to acknowledge the financial support and funding received from the European Union, as this research is part of the FP7-PEOPLE-2012-IAPP project "EiroCrete: Development of sustainable, lower carbon, pre-cast concrete infrastructure". This work actually represents the summary of the activity performed by the authors during reciprocal secondments. The kind support of Gannon Eco (Ireland), in the person of Mr. Nial Gannon, in providing the ceramic powders needed for this investigation is also gratefully acknowledged. The authors also thank MEng. Eduardo Ballesteros Ribera, MEng. Héctor David Méndez Figueroa, Mr. Alex Pellegri and Mr. Lorenzo Sgubbi, MEng. Marko Bunoza and MEng. Julian Mundija for their cooperation in performing the experimental tests and reducing the data, in partial fulfilment of the requirements for the respective achievement of their MSEng and BEng in Civil Engineering at Politecnico di Milano. 


\section{References}

[1] Neville, A.M. (2012). Properties of concrete, 5th edition, Prentice Hall, Pearson, San Francisco, CA, 846 pp., ISBN 0273755803 and 978-0273755807.

[2] Barros, J.A.O., Ferrara, L. and Martinelli, E. (eds.) (2017). Recent advances on green concrete for structural purposes. The contribution of the EU-FP7 project EnCoRe. Springer, pp. 427+x, ISBN 978-3-319-56797-6.

[3] Siddique R., Khatib J. And Kaur I. (2008). Use of recycled plastic in concrete: a review. Waste Management, 28: 1835-1852.

[4] Borg, R.P., Baldacchino, O. and Ferrara, L. (2016) Early age performance and mechanical characteristic of PET Fibre Reinforced Concrete. Construction and Building Materials, 108: 29-47.

[5] Zimbili, O., Salim W. and Ndambuki, M. (2014). A review on the usage of ceramic wastes in concrete producton. International Journal of Civil, Environmental, Structural, Construction and Architectural Engineering, 8, 91-95.

[6] Amorin, L.V., Lira, H.L. and Ferreira, H.C. (2003). Use of residential construction waste and residues from red ceramic industry in alternative mortars. ASCE Journal of Environmental Engineering, 129, 916-920.

[7] Vejmelová, E., Kulovaná, T., Keppert, M., Konvalinka, P., Ondráček, M., Sedlmajer, M. and Černy, R. (2012). Application of waste ceramics as active pozzolana in concrete production. Proceedings IACSIT Coimbatore Conferences, IACSIT Press, Singapore, 132-136.

[8] Raval, A.D., Patel, I.N. and Pitroda, J. (2013). Ceramic waste: effective replacement of cvement for establishing sustainable concrete. International Journal of Engineering Trends and technology, 4, 2324-2329.

[9] Ay, N. and Ünal, M. (2000). The use of waste ceramic tile in cement production. Cement and Concrete Research, 30, 497-499. 
[10] Puertas, F., García-Díaz, I., Barba, A., Gazulla, M.F., Palacios, M., Gomez, M.P., and Martínez-Ramírez, S. (2008), Ceramic wastes as alternative raw materials for Portland cement clinker production. Cement and Concrete Composites, 30, 798-805.

[11] Puertas, F., García-Díaz, I., Palacios, M., Gazulla, M.F., Gomez, M.P. and Orduña, M. (2010). Clinkers and cements obtained from raw mix containing ceramic waste as a raw material. Characterization, hydration and leaching studies. Cement and Concrete Composites, 32, 175-186.

[12] Senthamarai, RM. And Devadas Manoharan, P. (2005). Concrete with ceramix waste aggregate. Cement and Concrete Composites, 27, 910-913.

[13] Sato, R., Shigematsu, A., Nukushina, T. and Kimura, M. (2011). Improvement of properties of Portland blast furnace cement type B concrete by internal curing using ceramic roof material waste. ASCE Journal of Materials in Civil Engineering, 23, 777-782.

[14] Gonzalez-Corominas, A. and Exteberria, M., (2014). Properties of high performance concrete made with recycled fine ceramic and coarse mixed aggregates. Construction and Building Materials, $68,618-626$.

[15] Higashiyama, H., Yagishita, F., Sano, M. and Takahashi, O. (2012). Compressive strength and resistance to chloride penetration of mortars using ceramic waste as fine aggregate. Construction and Building Materials, 26, 96-101.

[16] Bignozzi, M.C. and Saccani, A., (2012). Ceramic waste as aggregate and supplementary cementing material: a combined action to contrast alkali silica reaction (ASR). Cement and Concrete Composites, 34, 1141-1148. 


\section{Tables}

Table 1. Mix. Composition of investigated cement pastes $\left(\mathrm{kg} / \mathrm{m}^{3}\right)$.

\begin{tabular}{ccccc}
\hline Mix-code & PCEM-ref & PCER-10 & PCER-30 & PCER-30wc \\
\hline Cement & 1632 & 1468 & 1142 & 1325 \\
Ceramic (either $1^{\text {st }}$ or $2^{\text {nd }}$ ) & & 105 & 316 & 367 \\
Water & 461 & 461 & 461 & 374 \\
Superplasticizer (polycarboxylate) & 14.2 & 14.2 & 14.2 & 23.3 \\
\hline
\end{tabular}

Table 2. Mix. Composition of investigated cement mortars $\left(\mathrm{kg} / \mathrm{m}^{3}\right)$.

\begin{tabular}{ccccccc}
\hline \multirow{2}{*}{ Mix-code } & $\begin{array}{c}\text { MCEM- } \\
\text { ref }\end{array}$ & $\begin{array}{c}\text { MCER- } \\
10\end{array}$ & $\begin{array}{c}\text { MCER- } \\
30\end{array}$ & $\begin{array}{c}\text { MCER- } \\
30 \mathrm{wc}\end{array}$ & $\begin{array}{c}\text { MCERS- } \\
30\end{array}$ & $\begin{array}{c}\text { MCERCS- } \\
30 \mathrm{wc}\end{array}$ \\
\hline Cement & 875 & 788 & 613 & 689 & 875 & 689 \\
Ceramic & & 57 & 170 & 190 & $278\left(2^{\text {nd }}\right)$ & $190\left(1^{\text {st }}\right)$ \\
${\left.\text { (either } 1^{\text {st }} \text { or } 2^{\text {nd }}\right)}$ & & & & & $278\left(2^{\text {nd }}\right)$ \\
Water & 247 & 247 & 247 & 194 & 247 & 194 \\
Superplasticizer & 7.3 & 7.3 & 7.3 & 26.7 & 12.7 & 43.3 \\
Sand & 1205 & 1205 & 1205 & 1205 & 843 & 843 \\
\hline
\end{tabular}

Table 3. Slump-flow diameters of investigated mortars (12 data for each mix $)-1^{\text {st }}$ ceramic powder

\begin{tabular}{ccccc}
\hline Mix-code & MCEM-ref & MCER-10 & MCER-30 & MCER-30wc \\
\hline Average diameter $(\mathrm{mm})$ & 298 & 333 & 322 & 297 \\
Std. dev. $(\mathrm{mm})$ & 36 & 17 & 14 & 10 \\
\hline
\end{tabular}

Table 4. Slump-flow diameters of investigated mortars (12 data for each mix $)-2^{\text {nd }}$ ceramic powder

\begin{tabular}{ccccccc}
\hline Mix-code & $\begin{array}{c}\text { MCEM- } \\
\text { ref }\end{array}$ & $\begin{array}{c}\text { MCER- } \\
10\end{array}$ & MCER- & MCER- & MCERS- & \multicolumn{2}{c}{ MCERCS- } \\
30 & $30 \mathrm{wc}$ & 30 & $30 \mathrm{wc}$ \\
\hline $\begin{array}{c}\text { Average diameter } \\
(\mathrm{mm})\end{array}$ & 295 & 330 & 305 & 311 & 309 & 245 \\
Std. dev. $(\mathrm{mm})$ & 50 & 10 & 25 & 10 & 13 & 13 \\
\hline
\end{tabular}

Table 5. MIP test results of mortars made with $1^{\text {st }}$ powder.

\begin{tabular}{cccc}
\hline Mix-code & MCEM-ref & MCER-10 & MCER-30 \\
\hline Total porosity $\%$ & 21.59 & 20.88 & 23.26 \\
Av. pore radius $(\mu \mathrm{m})$ & 0.0184 & 0.0143 & 0.0109 \\
Median pore radius $(\mu \mathrm{m})$ & 0.0264 & 0.0201 & 0.0142 \\
\hline
\end{tabular}


Figures

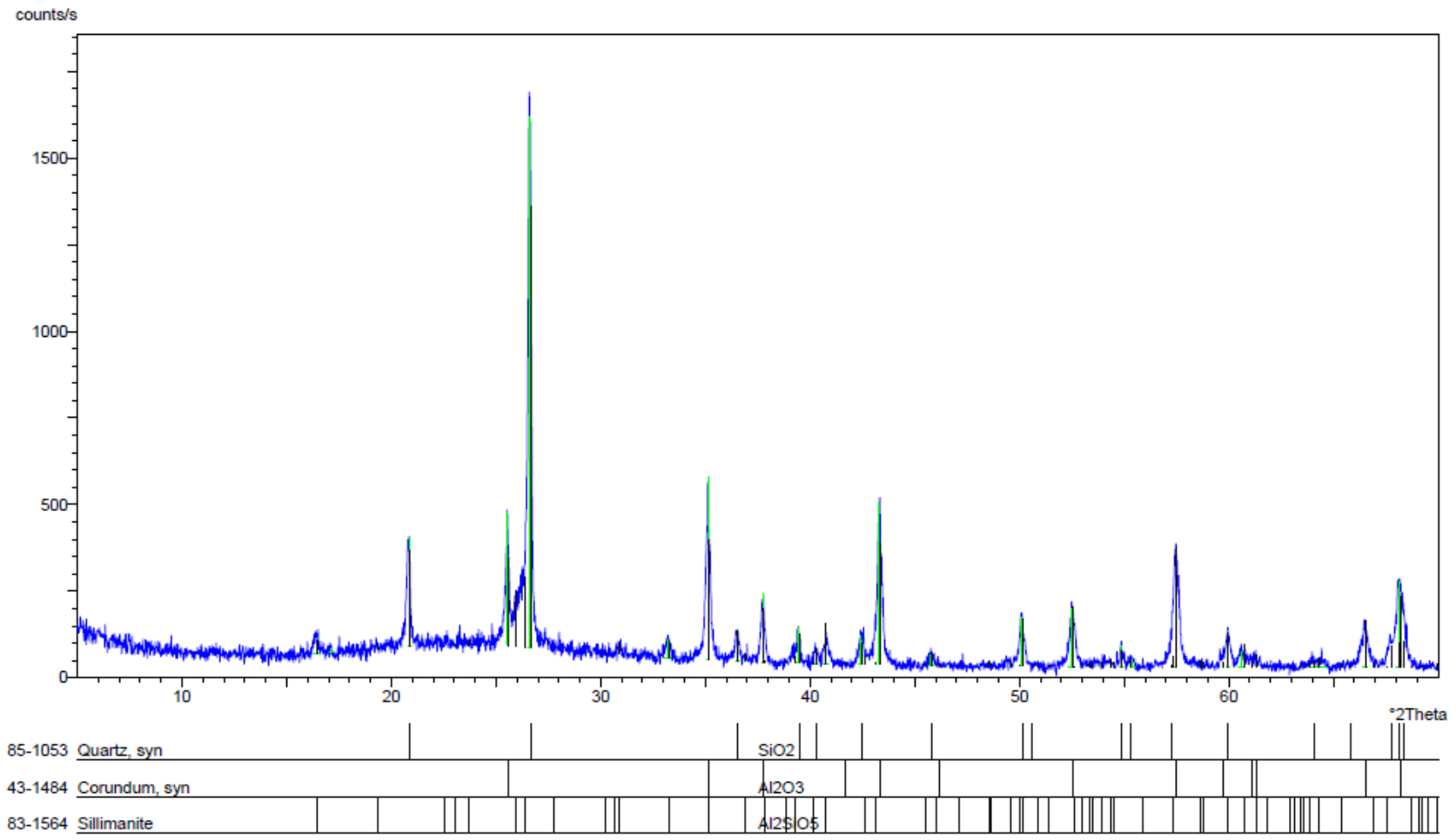

(a)

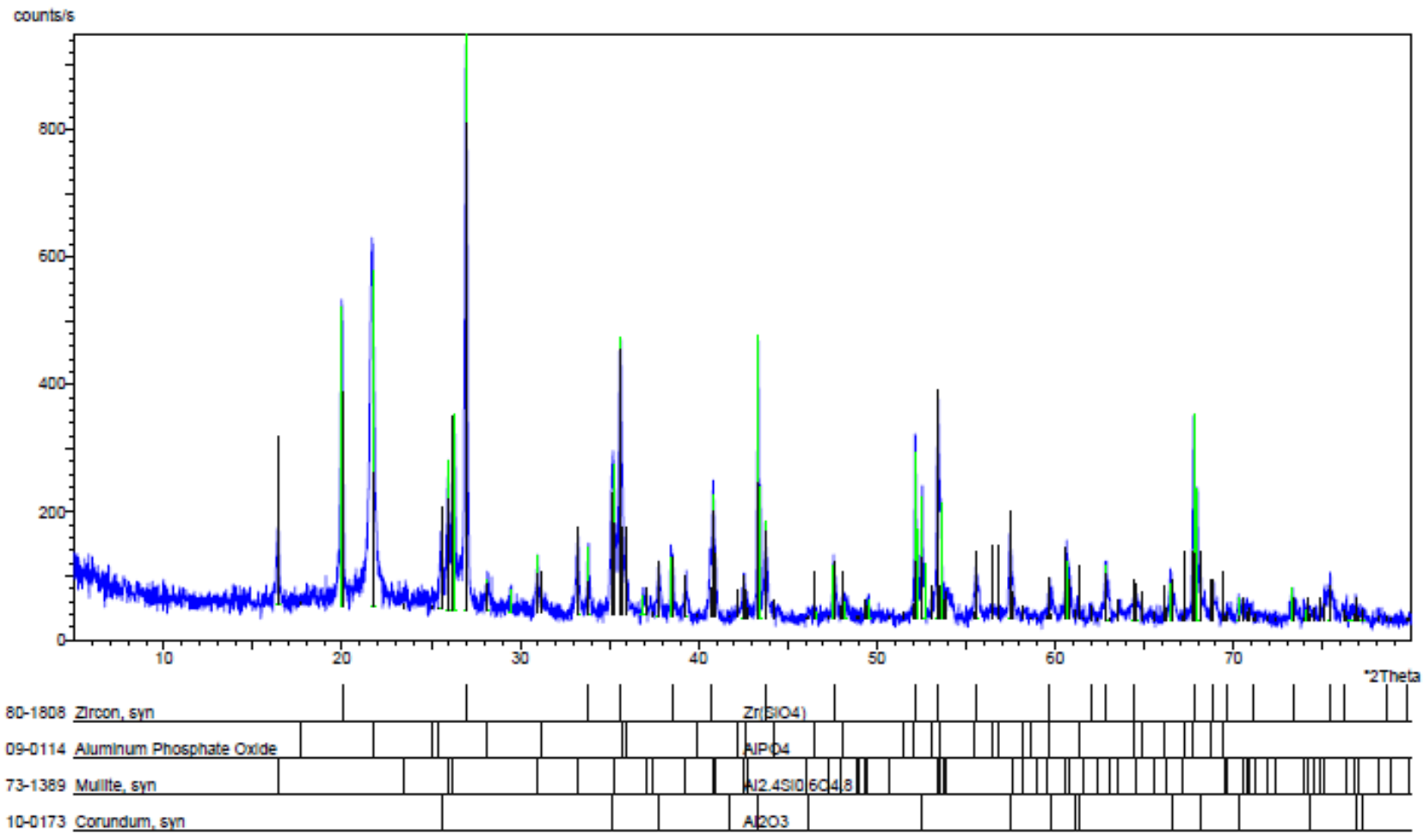

(b)

Figure 1 XRD analysis of $1^{\text {st }}$ (a) and $2^{\text {nd }}$ (b) ceramic powder 


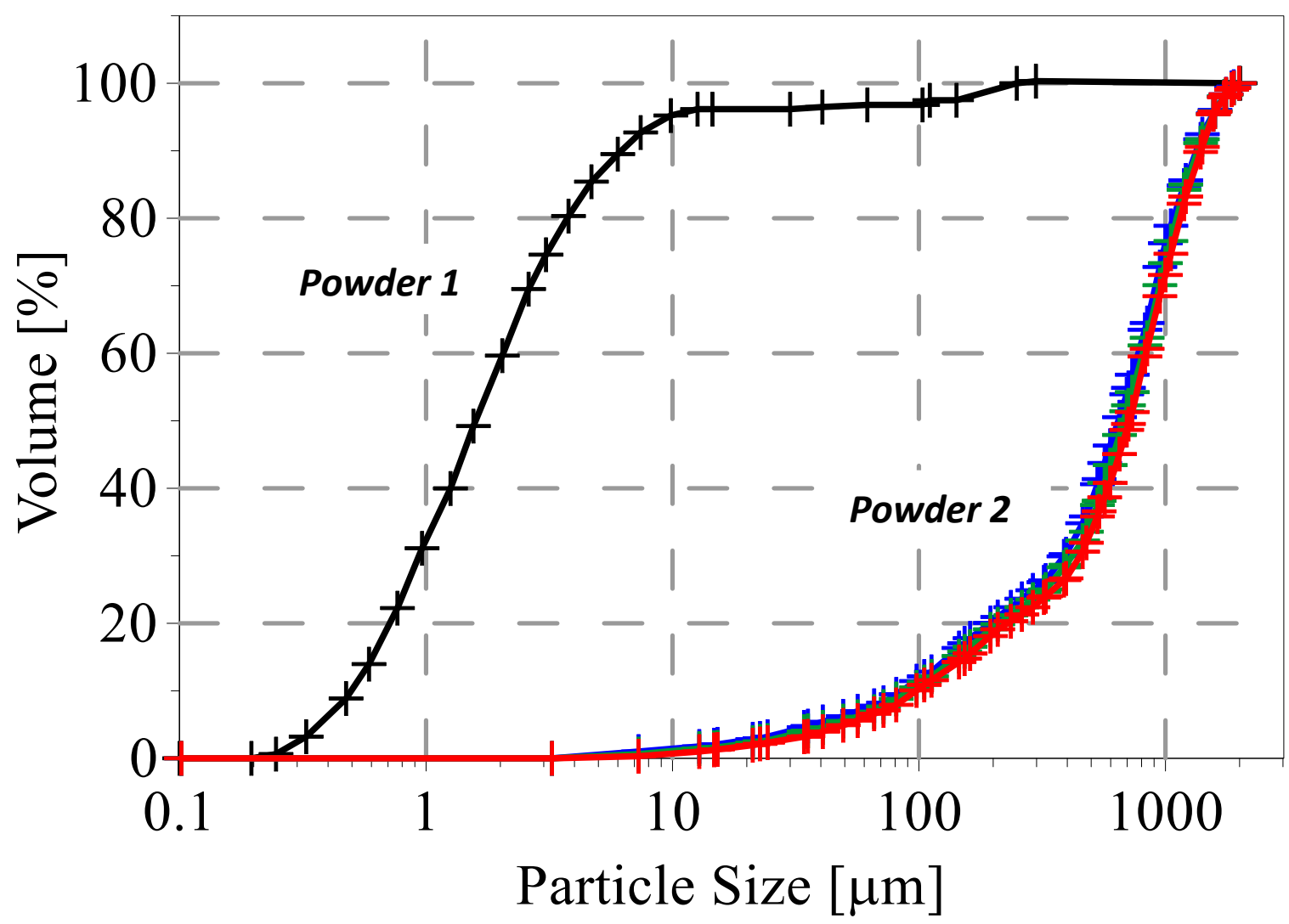

Figure 2. Cumulative particle size distribution for $1^{\text {st }}$ and $2^{\text {nd }}$ employed ceramic powders. 

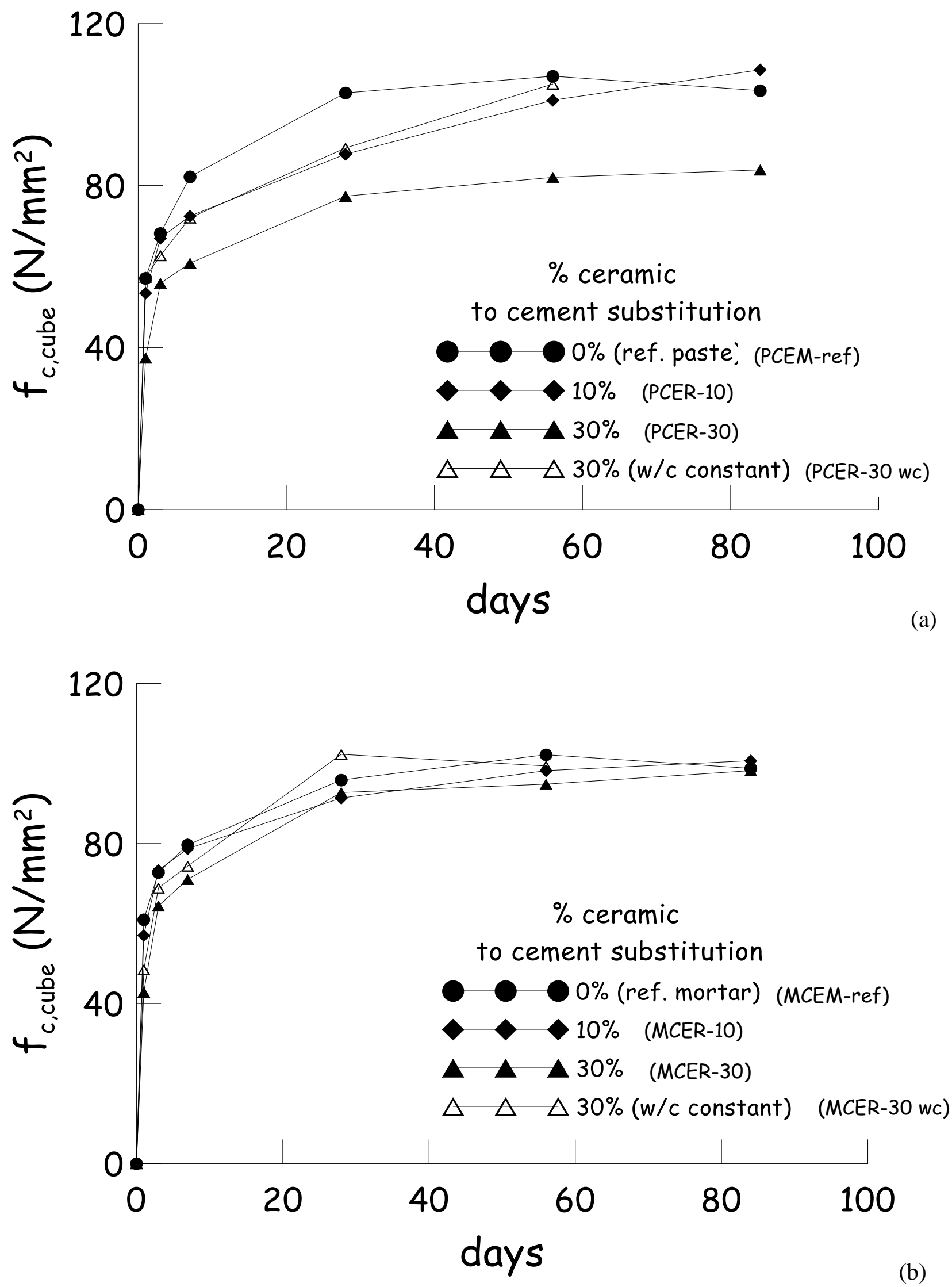

Figure 3. Time evolution of compressive strength for cement pastes (a) and mortars (b) made with $1^{\text {st }}$ ceramic powder. 

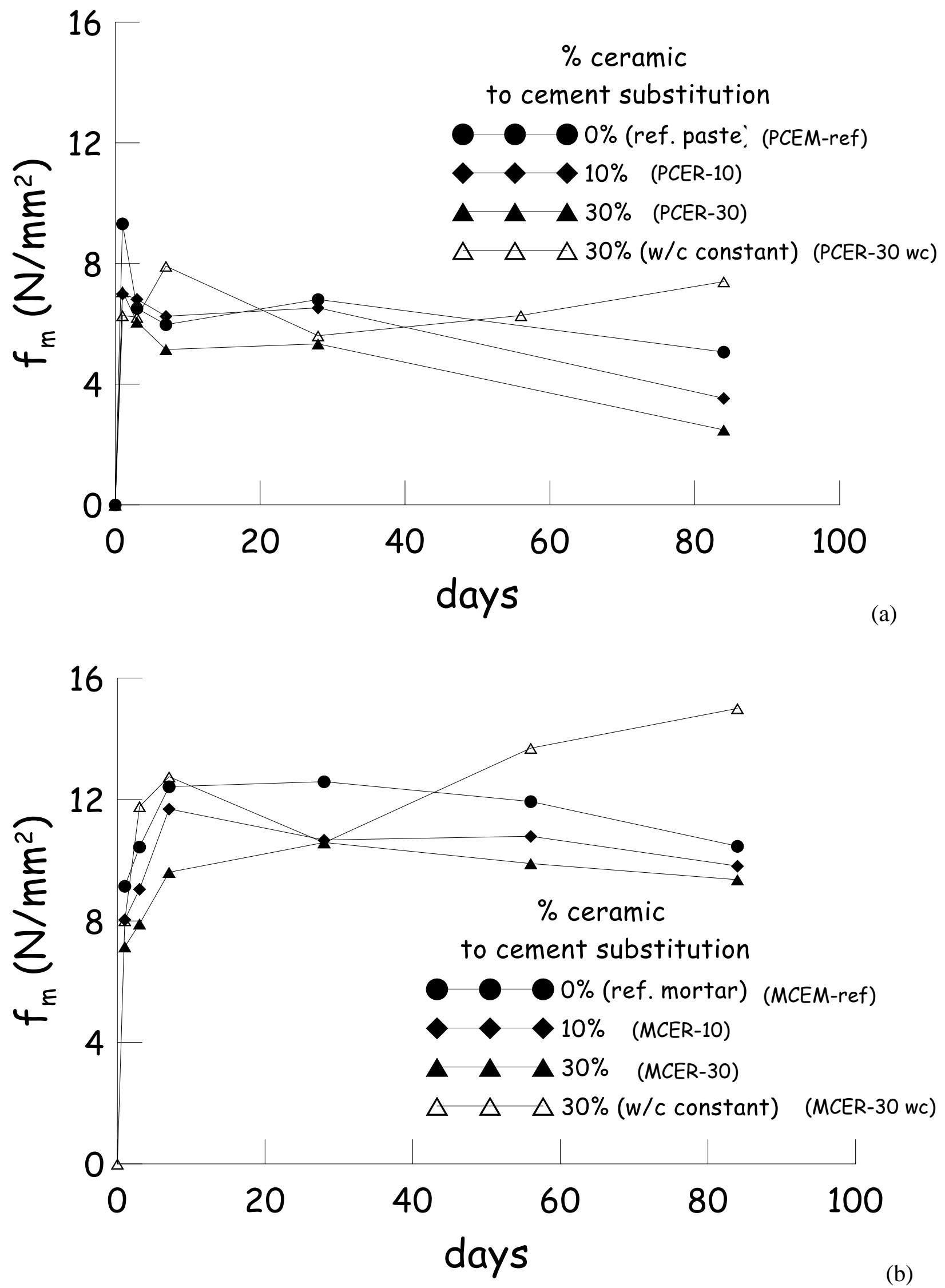

Figure 4. Time evolution of flexural strength for cement pastes (a) and mortars (b) made with $1^{\text {st }}$ ceramic powder. 

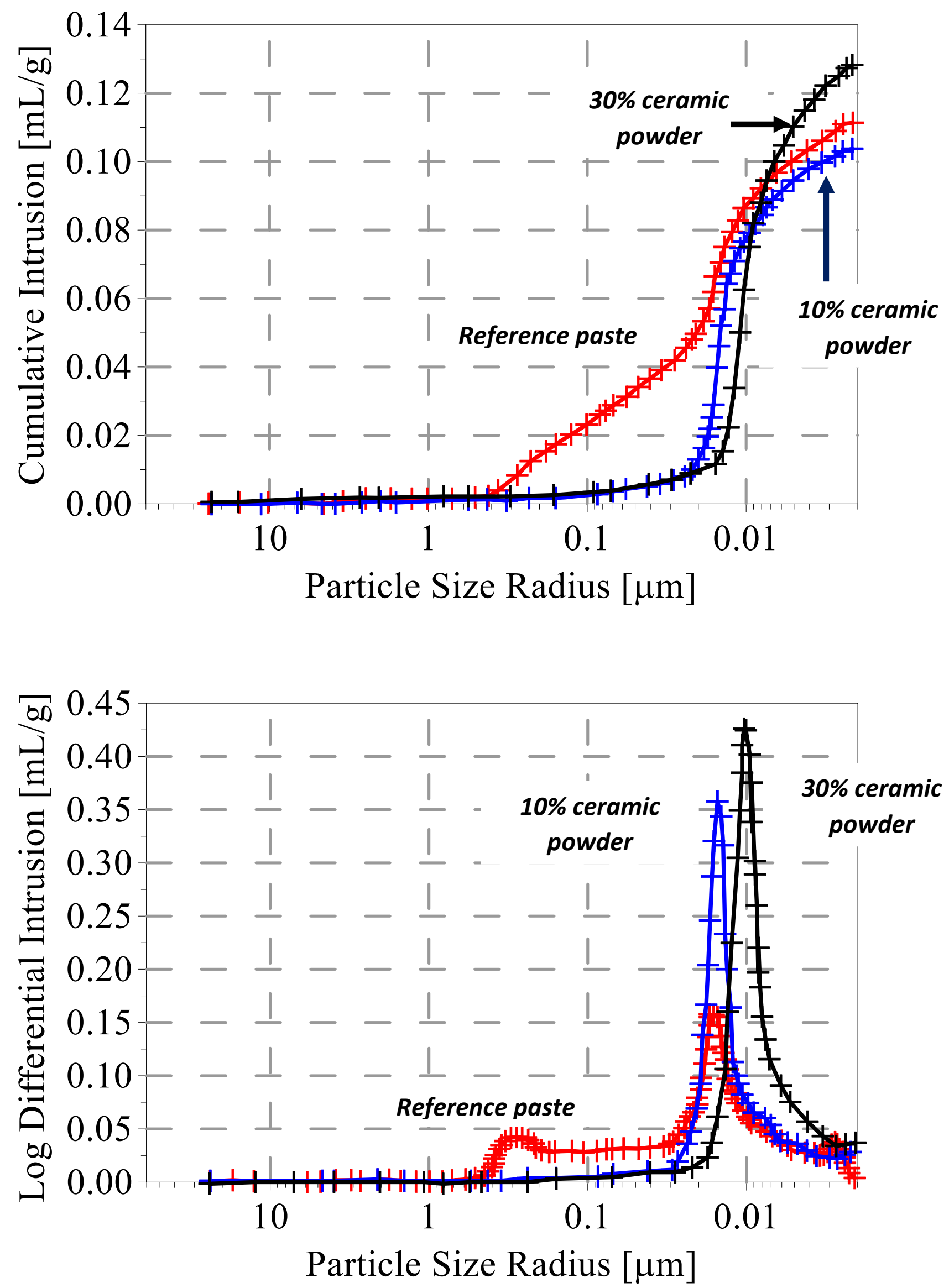

Figure 5: cumulative and differential pore size distribution for reference paste, paste with $10 \%$ and 
$30 \%$ replacement of cement with ceramic powder.
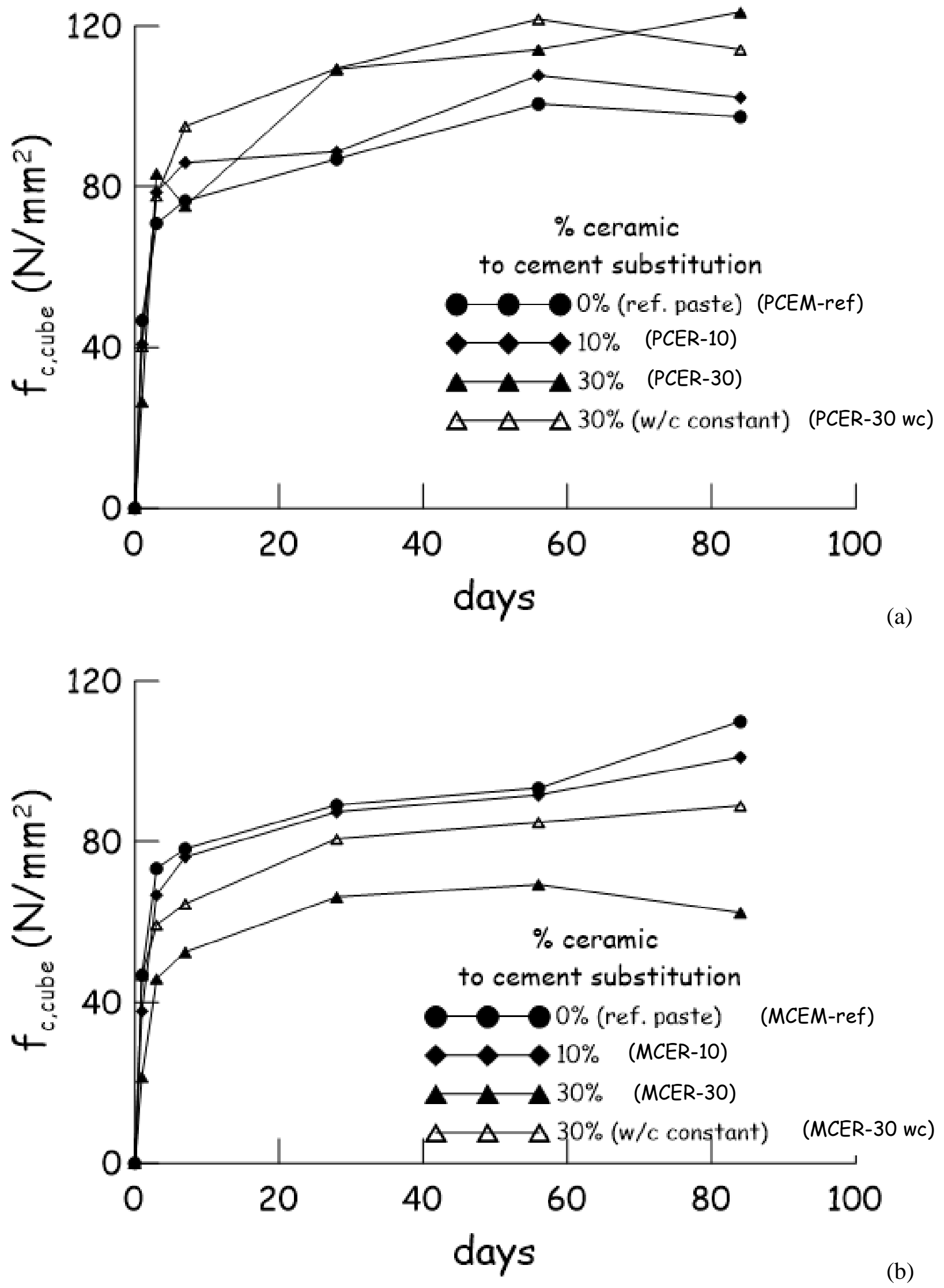

Figure 6. Time evolution of compressive strength for cement pastes (a) and mortars (b) made with 
$2^{\text {nd }}$ ceramic powder.
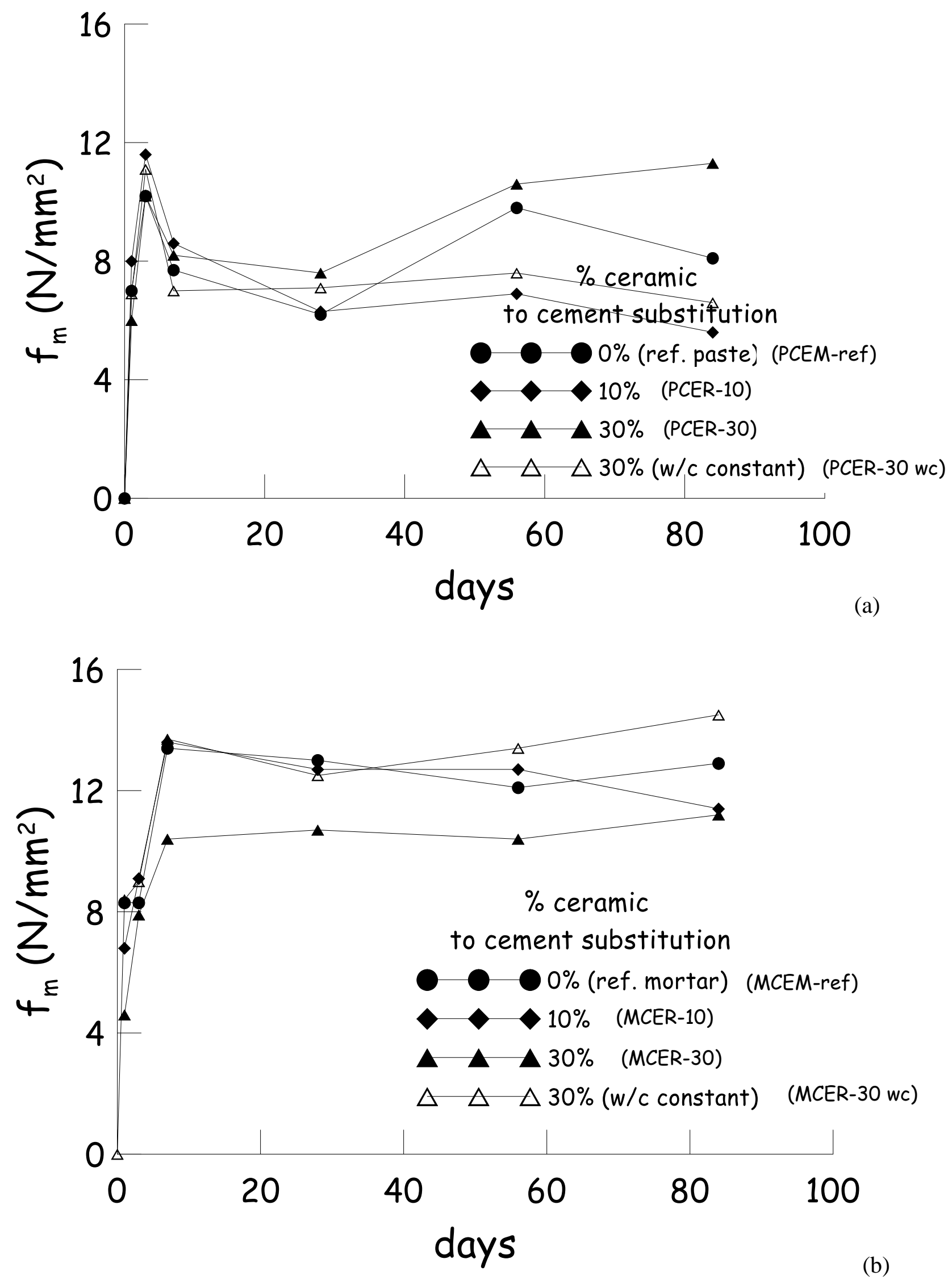

Figure 7. Time evolution of flexural strength for cement pastes (a) and mortars (b) made with $2^{\text {nd }}$ 
ceramic powder.
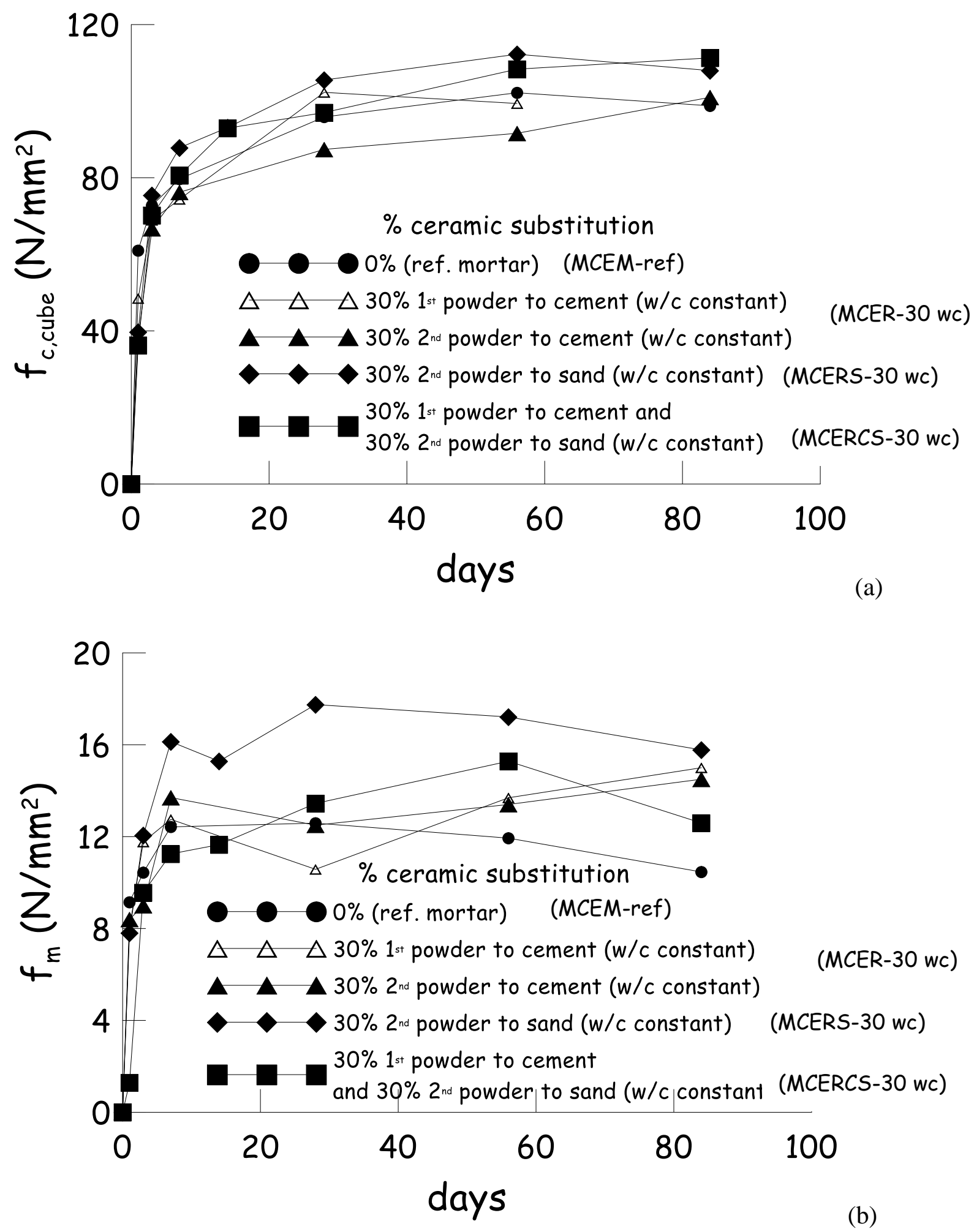

Figure 8. Time evolution of compressive (a) and flexural (b) strength for mortars made replacing either cement or/and sand with with $1^{\text {st }}$ and $2^{\text {nd }}$ ceramic ceramic powder. 

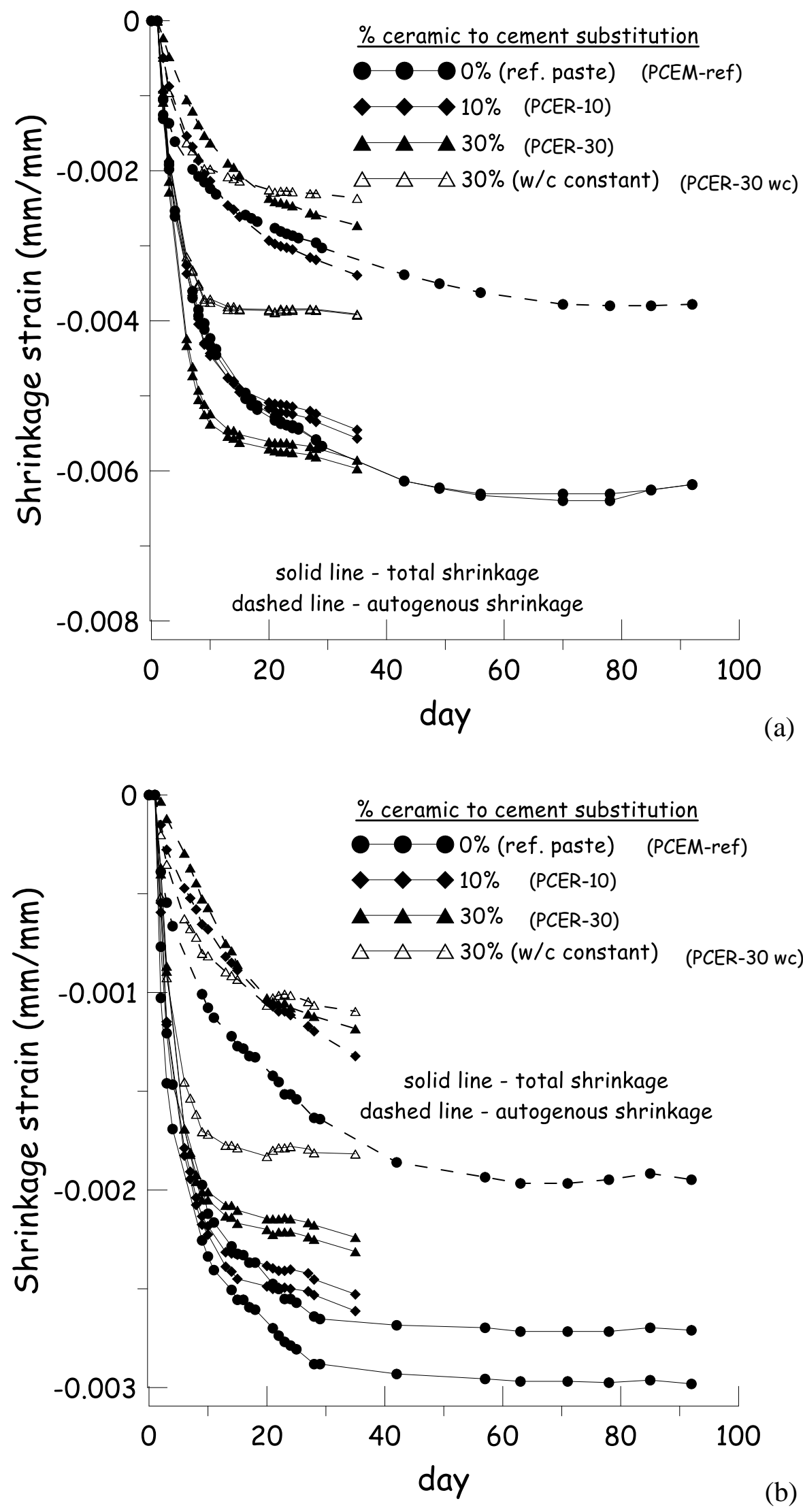

Figure 9. Time evolution of total free and autogenous shrinkage strain for cement pastes (a) and mortars (b) made with $1^{\text {st }}$ ceramic powder. 

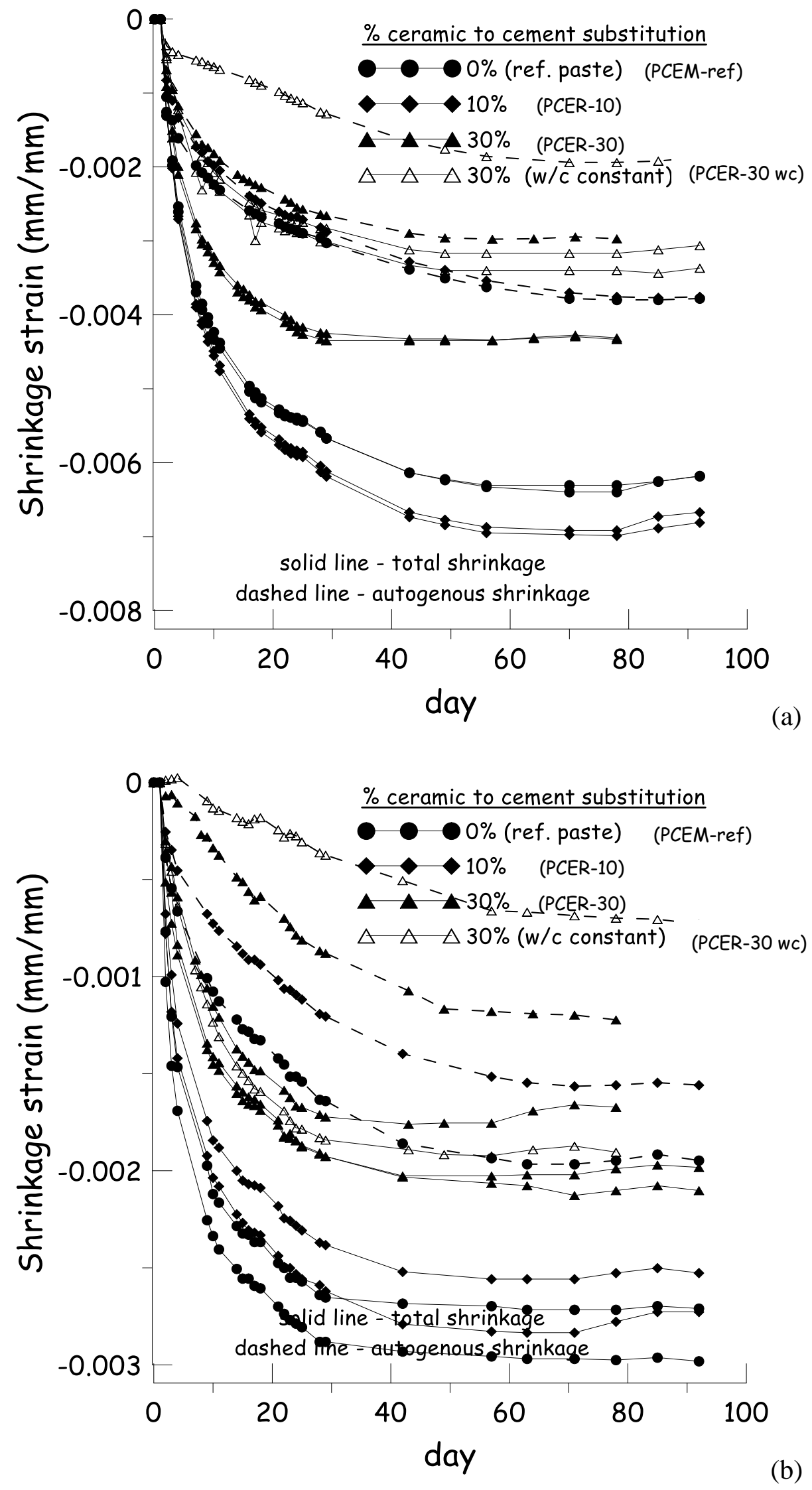

Figure 10. Time evolution of total free and autogenous shrinkage strain for cement pastes (a) and mortars (b) made with $2^{\text {nd }}$ ceramic powder. 


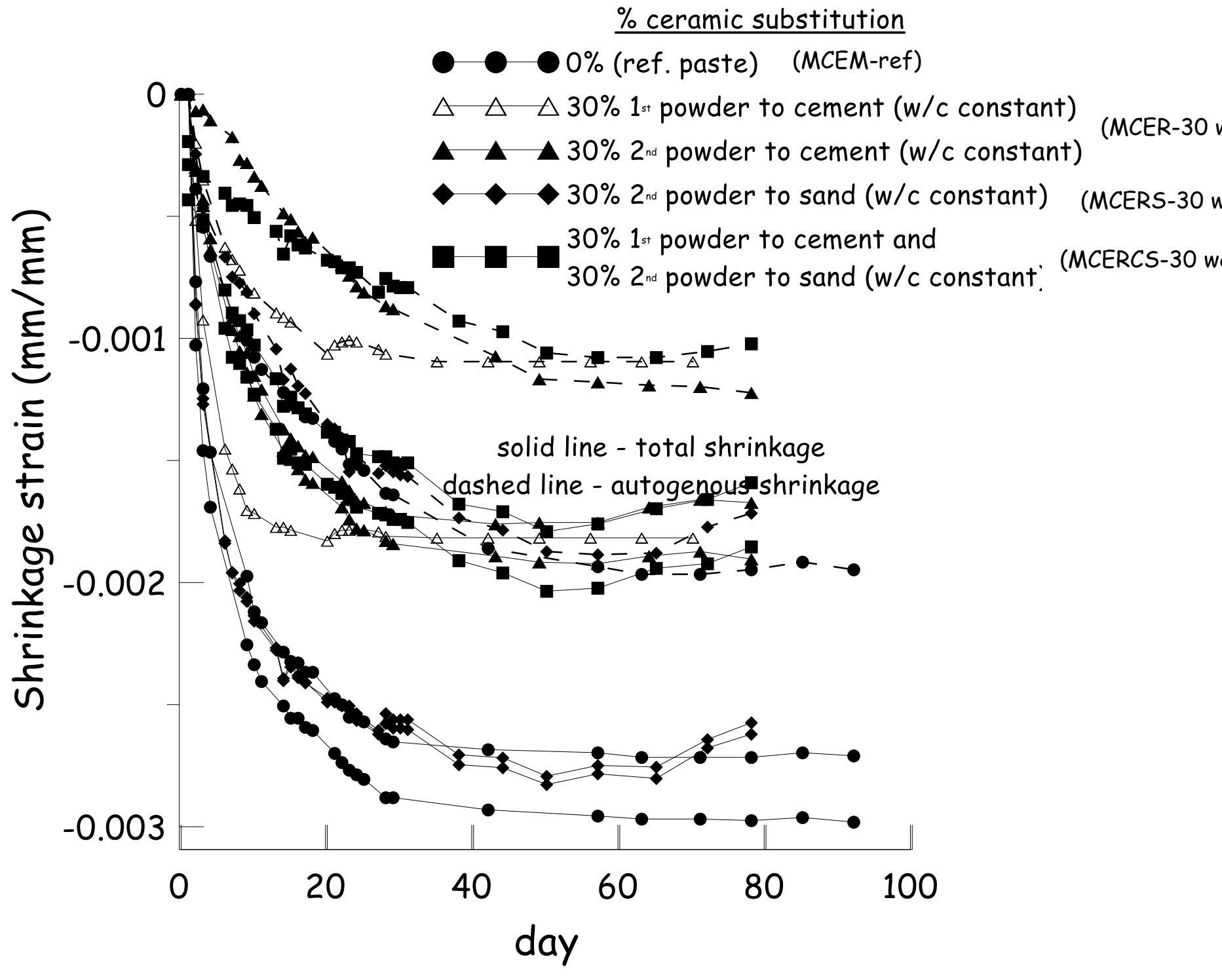

Figure 11. Time evolution of total free and autogenous shrinkage strain for mortars made replacing either cement or/and sand with with $1^{\text {st }}$ and $2^{\text {nd }}$ ceramic ceramic powder. 